Ferrata Storti Foundation

\title{
Human hematopoietic stem/progenitor cells display reactive oxygen species-dependent long-term hematopoietic defects after exposure to low doses of ionizing radiations
}

Haematologica 2020

Volume 105(8):2044-2055

\section{Correspondence: \\ MARIE-LAURE ARCANGELI \\ marie-laure.arcangeli@inserm.fr \\ Received: May 14, 2019. \\ Accepted: November 27, 2019. \\ Pre-published: November 28, 2019.}

doi:10.3324/haematol.2019.226936

Check the online version for the most updated information on this article, online supplements, and information on authorship \& disclosures: www. haematologica.org/content/105/8/2044

(C)2020 Ferrata Storti Foundation

Material published in Haematologica is covered by copyright. All rights are reserved to the Ferrata Storti Foundation. Use of published material is allowed under the following terms and conditions:

https://creativecommons.org/licenses/by-nc/4.0/legalcode. Copies of published material are allowed for personal or internal use. Sharing published material for non-commercial purposes is subject to the following conditions:

https://creativecommons.org/licenses/by-nc/4.0/legalcode, sect. 3. Reproducing and sharing published material for commercial purposes is not allowed without permission in writing from the publisher.

\author{
Elia Henry, ${ }^{* 1,2,3,4}$ Inès Souissi-Sahraoui, ${ }^{1,2,3,4}$ Margaux Deynoux, ${ }^{1,2,3,4}$ \\ Andréas Lefèvre, ${ }^{1,2,3,4}$ Vilma Barroca, ${ }^{1,2,3,4}$ Anna Campalans, ${ }^{3,4,5}$ \\ Véronique Ménard, ${ }^{3,4,6}$ Julien Calvo, ${ }^{1,2,3,4}$ Françoise Pflumio, ${ }^{\# 1,2,3,4}$ \\ and Marie-Laure Arcangeli ${ }^{\# 1,2,3,4}$
}

${ }^{1}$ INSERM, U1274, Laboratory "Niche, Cancer and Hematopoiesis"; 'CEA, DRF-JACOBIRCM-SCSR-LSHL, UMR “Genetic stability, Stem Cells and Radiation"; "UMR "Genetic stability, Stem Cells and Radiation" Université de Paris; ${ }^{4}$ UMR "Genetic stability, Stem Cells and Radiation", Université Paris-Saclay; ${ }^{5}$ CEA, DRF-JACOB-IRCM-SIGRR-LRIG, UMR "Genetic stability, Stem Cells and Radiation" and "UMR "Genetic stability, Stem Cells and Radiation", F-92265 Fontenay-aux-Roses, France

*EH and IS-S contributed equally as co-first authors.

${ }^{\#} F P$ and M-LA contributed equally as co-senior authors.

\section{ABSTRACT}

$\tau$ โT ematopoietic stem cells are responsible for life-long blood cell production and are highly sensitive to exogenous stresses. The effects of low doses of ionizing radiations on radiosensitive tissues such as the hematopoietic tissue are still unknown despite their increasing use in medical imaging. Here, we study the consequences of low doses of ionizing radiations on differentiation and self-renewal capacities of human primary hematopoietic stem/progenitor cells (HSPC). We found that a single 20 mGy dose impairs the hematopoietic reconstitution potential of human HSPC but not their differentiation properties. In contrast to high irradiation doses, low doses of irradiation do not induce DNA double strand breaks in HSPC but, similar to high doses, induce a rapid and transient increase of reactive oxygen species (ROS) that promotes activation of the p38MAPK pathway. HSPC treatment with ROS scavengers or p38MAPK inhibitor prior exposure to 20 $\mathrm{mGy}$ irradiation abolishes the $20 \mathrm{mGy}$-induced defects indicating that ROS and p38MAPK pathways are transducers of low doses of radiation effects. Taken together, these results show that a $20 \mathrm{mGy}$ dose of ionizing radiation reduces the reconstitution potential of HSPC suggesting an effect on the self-renewal potential of human hematopoietic stem cells and pinpointing ROS or the p38MAPK as therapeutic targets. Inhibition of ROS or the p38MAPK pathway protects human primary HSPC from low-dose irradiation toxicity.

\section{Introduction}

Hematopoietic stem cells (HSC) give rise to all blood cell types over the entire life of an organism. In adult mammals, they are located in very specific microenvironments of the bone marrow (BM), allowing maintenance of HSC functions. ${ }^{1}$ In humans, $\mathrm{HSC}$ are enriched in the $\mathrm{CD} 34^{+} \mathrm{CD} 38^{\text {low }} \mathrm{CD} 90^{+} \mathrm{CD} 45 \mathrm{RA}^{-}$cell population that also contains immature progenitors, hereafter called HSPC.,3 Hematopoietic stem/progenitor cells (HSPC) are multipotent and mainly slow cycling cells. They possess a self-renewal potential that allows them to sustain the continuous generation of blood cells. Quiescence and self-renewal are regulated by several extrinsic factors, such as cytokines, extracellular matrix proteins and adhesion molecules,, 45 as well as intrinsic factors, such as transcription factors (TAL1, ${ }^{6.8}$ GATA-2, etc. ${ }^{9}$ ), proteins implicated in DNA damage repair pathways, ${ }^{10-12}$ and cell cycle regulators. ${ }^{13-15}$ Mutations in genes involved in DNA repair induce BM failure with exhaustion of the 
HSC pool, demonstrating that preserving genome integrity is crucial for HSC long-term maintenance (reviewed by Biechonski and Milyavsky). ${ }^{16}$ For instance, ku80, lig 4 and atm-deficient mice exhibit defects in HSC maintenance and self-renewal. ${ }^{10-12}$ Atm-deficient HSC harbor increased levels of reactive oxygen species (ROS) responsible for their loss of hematopoietic reconstitution capacity ${ }^{10}$ that can be rescued by treatment with the antioxidant $\mathrm{N}$-acetylcystein (NAC). Indeed, increased ROS in HSC induce their differentiation and their exhaustion ${ }^{17,18}$ and quiescent HSC with the lowest level of ROS have the highest hematopoietic reconstitution potential compared to 'activated' HSC harboring higher ROS levels. ${ }^{17}$ Interestingly, in mouse and human, ROS and DNA damage accumulate in HSC upon serial transplantation resulting in decreased self-renewal capacities. NAC-treated HSC are protected against the accumulation of oxidative DNA damage..$^{18,19}$

Ionizing radiations (IR) represent the main source of DNA damage and ROS. Importantly, the human population is increasingly exposed to low doses of IR (LDIR, $<100 \mathrm{mGy}$ ) due to the recurrent use of medical imaging. ${ }^{20}$ Studies have shown that combinations of several computed tomography (CT) scans (thoracic or cranial) can increase the risk of developing cancer. ${ }^{21}$ Indeed, having more than five CT scans (corresponding to a cumulative dose of $30 \mathrm{mGy}$ ) can lead to a 3-fold increase in the risk of developing pediatric leukemia. Moreover, a recent study showed that $20 \mathrm{mGy}$ LDIR affects the fundamental properties of HSC in mouse. ${ }^{22}$ In this context, it is crucial to study the consequences of LDIR exposure in human cells, in particular in human HSC. Here we show through combining in vitro and in vivo studies that a single acute $20 \mathrm{mGy}$ LDIR decreases human HSPC serial clonogenic and reconstitution potentials, and that these effects are mediated through a ROS/p38MAPK-dependent signaling pathway.

\section{Methods}

\section{Primary cells}

Cord blood (CB) samples were collected from healthy infants with the informed written consent of the mothers according to the Declaration of Helsinki. Samples were obtained in collaboration with the Clinique des Noriets, Vitry-sur-Seine, and with the Cell Therapy Department of Hôpital Saint-Louis, Paris, France. Samplings and experiments were approved by the Institutional Review Board of INSERM (Opinion n. 13-105-1, IRB00003888). $\mathrm{CD}_{4}{ }^{+}$cells were purified by immuno-magnetic selection using a CD34 MicroBeads kit (Miltenyi Biotec, Paris, France). For each experiment, we used a pool of $\mathrm{CD} 34^{+}$cells from different healthy infants to diminish individual variability.

\section{Low dose of ionizing radiations}

20 mGy LDIR was delivered with a dose rate of 20 $\mathrm{mGy} / \mathrm{minute}$ ( $\mathrm{min}$ ) using a Cobalt 60 Irradiator (Alcyon). 2.5 Gy was delivered with a dose rate of $1 \mathrm{~Gy} / \mathrm{min}$.

\section{Flow cytometry and cell sorting}

$\mathrm{CD} 34^{+} \mathrm{CD} 38^{\text {low }}$ cells and $\mathrm{CD} 34^{+} \mathrm{CD} 38^{\text {low }} \mathrm{CD} 45 \mathrm{RA}^{-} \mathrm{CD} 90^{+} \mathrm{HSPC}$ were isolated after labeling with human specific monoclonal antibodies (MoAbs, see Online Supplementary Table S1 for details). Cell sorting was performed using either a Becton Dickinson (BD)FACS-ARIA3 SORP or a BD-FACS-Influx (laser 488, 405, 355, 561 and $633, \mathrm{BD}$ Bioscience). Flow cytometry experiments are described in the Online Supplementary Methods.

\section{Transplantation assays}

NOD.Cg-Prkdc(scid) Il2rg(tm1Wjll)/SzJ (NSG) mice (Jackson Laboratory, Bar Harbor, ME, USA) were housed in the pathogenfree animal facility of IRCM, CEA, Fontenay-aux-Roses, France. Adult 8-12-week old NSG mice received a 3 Gy sublethal irradiation using a GSRD1 $\gamma$-irradiator (source Cesium137, GSM) and were anesthetized with isoflurane before intravenous retro-orbital injection (i.v.) of human cells as described in the Online Supplementary Methods. All experimental procedures were carried out in compliance with French Ministry of Agriculture regulations (animal facility registration n.: A9203202, Supervisor: Michel Bedoucha, APAFIS \#9458-2017033110277117v2) for animal experimentation and in accordance with a local ethical committee (\#44).

\section{Immunofluorescence}

Immunofluorescence was performed on cell-sorted HSPC irradiated and incubated $30 \mathrm{~min}, 1$ hour $(\mathrm{h})$, or $3 \mathrm{~h}$ at $37^{\circ} \mathrm{C}$ in MyeloCult medium, as previously described..$^{22-24}$ Details of the methods used are available in the Online Supplementary Methods.

\section{Drug treatments}

$\mathrm{CD}_{4} 4^{+}$cells or $\mathrm{CD} 34^{+} \mathrm{CD} 38^{\text {low }} \mathrm{CD} 45 \mathrm{RA}^{-} \mathrm{CD} 90^{+} \mathrm{HSPC}$ were treated with several drugs as described in the Online Supplementary Methods.

\section{Colony forming unit-cell assay}

Colony forming unit-cell assay (CFU-C) and serial platings were performed as previously described; ${ }^{6}$ see Online Supplementary Methods for details. Depending on CB pool samples, 60-80 colonies were generated from 500 HSPC non-irradiated or irradiated at $20 \mathrm{mGy}$.

\section{Primary and extended long-term culture initiating cell assays}

Long-term culture initiating cell assay was performed as previously described ${ }^{6}$ and is described in detail in the Online Supplementary Methods.

\section{Intracellular flow cytometry}

Ki67, cleaved caspase 3, phospho-p38MAPK (P-p38, phosphorylation on Thr180/Tyr182), phospho-ATM, p53 and phosphop53 staining were performed as previously described ${ }^{4}$ (Ki67) and according to the manufacturer's instructions, respectively. More details can be found in the Online Supplementary Methods.

\section{Carboxyfluorescein diacetate succinimidyl ester staining}

$3 \times 10^{5} \mathrm{CD} 34^{+}$cells were labeled with carboxyfluorescein diacetate succinimidyl ester (CFSE) (2.5 $\mu \mathrm{M}$, Sigma, France) and cultured in StemSpan medium supplemented with cytokines (Stem Cell Technologies), as described in the Online Supplementary Methods.

\section{Reactive oxygen species quantification and mitochondria activity assay}

Reactive oxygen species quantification was performed with fresh $\mathrm{CD}_{3} 4^{+}$cells using CellRox Orange reagent following the manufacturer's instructions (ref. C10443, Molecular Probes, ThermoFisher Scientific). Mitochondrial activity assay was performed using mitotracker green (MTG) and TMRE products, according to the manufacturer's instructions (Molecular Probes, ThermoFisher Scientific).

\section{Statistical analysis}

Mann and Whitney (M\&W) and Kruskal and Wallis (K\&W) 
A

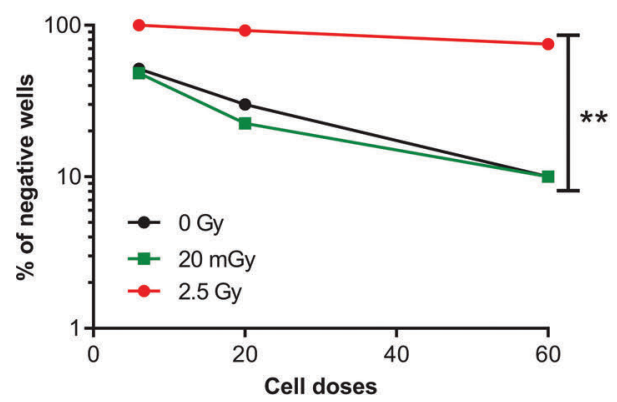

B

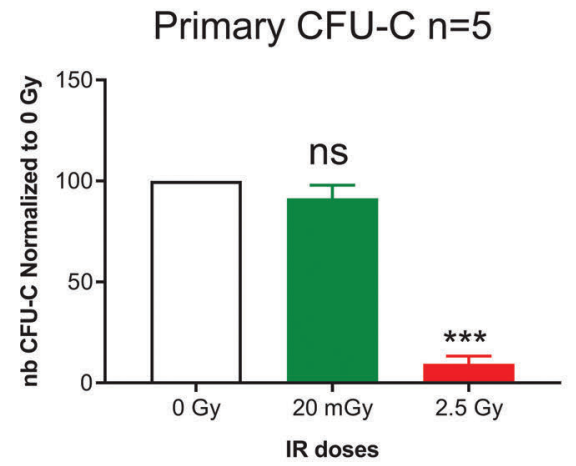

\begin{tabular}{|lcc|}
\hline IR doses & Frequency & IC $95 \%$ \\
\hline 0 Gy & $1 / 15$ & $1 / 11 ; 1 / 19$ \\
\hline $20 \mathrm{mGy}$ & $1 / 13$ & $1 / 10 ; 1 / 17$ \\
\hline $2.5 \mathrm{~Gy}$ & $1 / 272$ & $1 / 136 ; 1 / 541$ \\
\hline
\end{tabular}

C

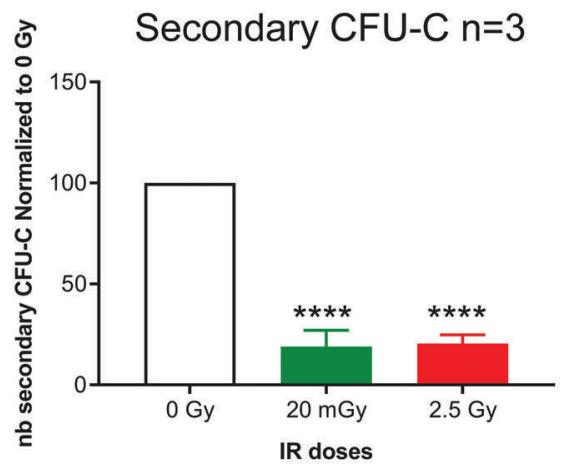

Figure 1. Low doses (LD) of ionizing radiations (IR) exposure of human hematopoietic stem progenitor cells (HSPC) leads to deficient serial colony forming unitcell assay (CFU-C) and primary and extended long-term culture initiating cell (LTC-IC) potentials. CD34 ${ }^{+} \mathrm{CD}^{\mathrm{S}} 8^{\text {low }} \mathrm{CD} 45 \mathrm{RA}-\mathrm{CD} 90^{+} \mathrm{HSPC}$ were sorted from pools of independent cord blood (CB) samples by cell sorting and exposed to the indicated IR doses prior to in vitro cultures. (A) LTC-IC assay in limiting dilution (pool of 2 experiments, 120 wells/IR dose). Irradiated CD34+ ${ }^{+}$CD38 $8^{\text {low }}$ CD45RA- CD90 ${ }^{+}$HSPC were seeded on MS5 stromal cells in limiting dilution for five weeks then plated in methylcellulose for 12 days. LTC-IC frequency was calculated using LCALC software. (B) Primary CFU-C assay (cumulative results from 4 independent experiments with HSPC isolated from 4 independent pools of CB samples). HSPC (500 cells/plate) were plated in CFU-C condition for $12-14$ days and the number (nb) of CFU-C was quantified. Results are normalized to the non-irradiated conditions. (C) Primary CFU-C were pooled and replated in methylcellulose for $12-14$ days. Shown are the $\mathrm{nb}$ of secondary CFU-C. Results are normalized to the sham-irradiated conditions (cumulative results from 3 independent experiments). Results are shown as mean \pm standard error of mean. $* * P<0.01, * * * P<0.001, * * * * P<0.0001$ (Mann-Whitney statistics).

non-parametric statistical analyses were used. ${ }^{*} P<0.05,{ }^{* *} P<0.01$, ${ }^{* * *} P<0.001,{ }^{* * * *} P<0.0001$.

\section{Results}

\section{A 20 mGy dose of irradiation decreases serial replating capacity of human hematopoietic stem/progenitor cells}

To understand the impact of HSPC exposure to LDIR, we first performed serial long-term culture initiating cell (LTC-IC) and CFU tests as surrogate assays to study human HSPC properties, i.e. self-renewal and differentiation capacities. ${ }^{25-27}$ Human $\mathrm{CD} 34^{+} \mathrm{CD} 38^{\text {low }} \mathrm{CD} 45 \mathrm{RA}-\mathrm{CD} 90^{+}$ HSPC were purified, irradiated and cultured with the MS5 stromal cell line in LTC medium for five weeks or plated directly in semi-solid methylcellulose cultures. In LTC-IC limiting dilution analyses, every single well was harvested independently at the end of the culture and plated in CFU$\mathrm{C}$ assay. The LTC-IC frequency obtained after a $20 \mathrm{mGy}$ irradiation of HSPC was similar to the LTC-IC frequency of sham-irradiated HSPC (1/15) suggesting that LDIR do not affect LTC-IC frequency. In contrast, a high (2.5 Gy) irradiation dose induced a drastic drop in LTC-IC frequency $(1 / 272)$ (Figure 1A). In addition, 2.5 Gy-irradiated HSPC directly seeded in CFU-C conditions after IR produced very few colonies compared to control cells whereas 20 mGy-irradiated HSPC generated a similar number of CFU$\mathrm{C}$ to sham-irradiated HSPC (Figure $1 \mathrm{~B}$ and Online Supplementary Figure S1A). No difference in the quality of CFU-C was observed between sham and $20 \mathrm{mGy}$ conditions (Online Supplementary Figure S1B). These primary LTC-IC and primary CFU-C assays show that $20 \mathrm{mGy}$ LDIR do not alter HSPC frequency and clonogenicity in vitro and do not induce any myelo/erythroid differentiation bias in primary cultures (Online Supplementary Figure $S 1 B)$. To characterize whether LDIR have deleterious effects on human HSPC self-renewal potential in vitro, serial replatings were performed for both CFU-C and LTC-IC assays. ${ }^{25-27}$ We observed that $20 \mathrm{mGy}$ and 2.5 Gy-irradiated $\mathrm{CD} 34^{+} \mathrm{CD} 38^{\text {low }} \mathrm{CD} 45 \mathrm{RA}^{-} \mathrm{CD} 90^{+} \mathrm{HSPC}$ produced lower numbers of secondary colonies in contrast to sham-irradiated HSPC, showing that $20 \mathrm{mGy}$ alters their serial clonogenic potential (Figure 1C and Online Supplementary Figure S1C). This result was also obtained after picking up and replating individual primary CFU-GM colonies (Online Supplementary Figure S1D). In the case of LTC-IC, secondary/extended cultures were initiated using cells expressing high CD34 surface expression (CD34 $\left.{ }^{\mathrm{hi}}\right)$, purified after the initial five weeks of LTC-IC culture (Online Supplementary Figure $S 1 E$ ) and seeded for five additional weeks in LTCIC conditions at limiting dilution. Of note, we were not 
A

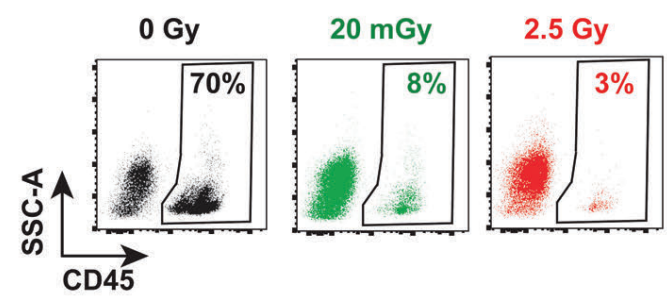

C

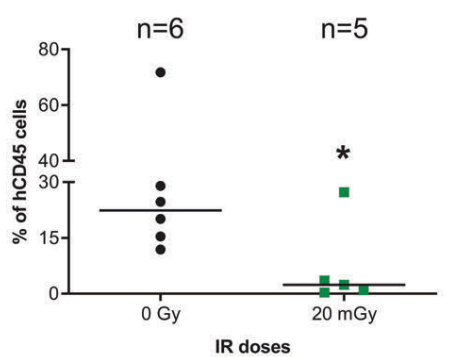

B
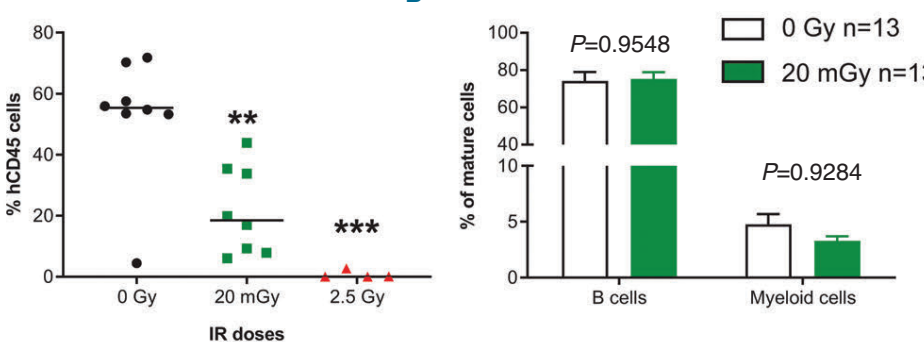

D

Gated on hCD45+ cells

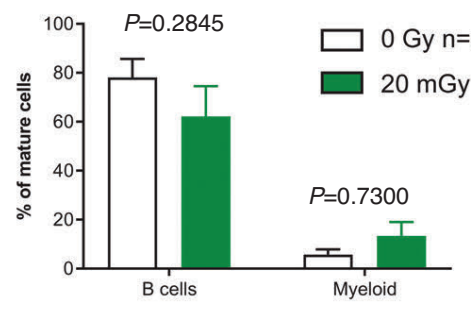

Figure 2. Hematopoietic reconstitution capacities of human hematopoietic stem cells (HSC) after in vivo exposure to low doses (LD) of ionizing radiations (IR). NSG mice were transplanted with $5.10^{4} \mathrm{CD} 34^{+} \mathrm{CB}$ cells and 13 to 16 weeks post graft mice were irradiated or not with the indicated doses then immediately sacrificed. Bone marrow (BM) cells were recovered and characterized by flow cytometry (Online Supplementary Figure S2A and B). An equivalent of 5.10 ${ }^{4} \mathrm{CD} 34^{+} \mathrm{CD} 19^{-} \mathrm{BM}$ cells were injected in secondary recipient mice. (A) Dot plots of representative engraftment levels (left: human hCD45 ${ }^{+}$cells) in secondary recipient mice and human engraftment levels obtained in the BM of 9 secondary NSG mice (right: 2 independent experiments are pooled). Results of a third experiment is shown in Online Supplementary Figure S2D since engraftment levels of control mice were lower. (B) Proportion of engrafted human B cells and myeloid cells based respectively on CD19 and CD14/CD15 expression gated in human CD45 ${ }^{+}$cells, in secondary recipient mice. (C) Human hematopoietic reconstitution of CD34 ${ }^{+}$CD38 $8^{\text {low }}$ Lin ${ }^{\text {neg }}$ BM cells purified by cell sorting from primary mice and transplanted in secondary recipient mice. Shown are human cell reconstitution in the BM of secondary recipient mice 13 weeks later. (D) Proportion of engrafted human B cells and myeloid cells gated within human CD45 cell compartment in secondary mice after human CD34 CD38 ${ }^{\text {low }}$ Lin $^{\text {neg }} \mathrm{BM}$ cell transplants. Results are shown as mean \pm standard error of mean. $* P<0.05 ; * * P<0.01, * * * P<0.001$ (Mann-Whitney statistics).

able to perform such extended LTC-IC with the $2.5 \mathrm{~Gy}$ condition due to very low cell quantities in the cultures. Interestingly, there was a 2 -fold decrease in the extended LTC-IC frequency of $20 \mathrm{mGy}$-irradiated HSPC compared to sham-irradiated HSPC (1/275 vs. 1/128) (Online Supplementary Figure S1F) showing a defect in long-term HSPC maintenance. This decrease in secondary LTC-IC frequency induced by $20 \mathrm{mGy}$ LDIR was also found in bulk culture conditions with 20 mGy-irradiated HSPC generating fewer CFU-C than sham-irradiated cells after secondary LTC-IC cultures (Online Supplementary Figure $S 1 G)$. Taken together, these results suggest that a single exposure to $20 \mathrm{mGy}$ LDIR impairs the in vitro self-renewal potential of human $\mathrm{CD} 34^{+} \mathrm{CD} 38^{\text {low }} \mathrm{CD} 45 \mathrm{RA}^{-} \mathrm{CD} 90^{+} \mathrm{HSPC}$.

\section{A 20 mGy dose of irradiation decreases human hematopoietic stem/progenitor cell hematopoietic reconstitution potential}

We then studied the effect of $20 \mathrm{mGy}$ LDIR on in vivo HSC functions. To do so, NSG mice were first engrafted with human $\mathrm{CD} 34^{+}$cells. Sixteen weeks later, once human hematopoiesis was stabilized, engrafted mice were exposed to 0,20 mGy and 2.5 Gy IR doses and sacrificed immediately after irradiation. Bone marrow (BM) cells were harvested and phenotype analysis was performed. The levels of human $\mathrm{CD} 45^{+}$cells and the percentage of $\mathrm{Lin}^{\text {neg }} \mathrm{CD} 34^{+}$cells recovered from NSG BM were similar in the irradiated and non-irradiated groups (Online Supplementary Figure S2A and B). Furthermore, no increase of apoptosis of human cells engrafted in NSG mouse BM was observed in mice irradiated at $20 \mathrm{mGy}$ compared to non-irradiated mice (Online Supplementary Figure S2C). To study the consequences of irradiation on human HSC functions (i.e. reconstitution and differentiation potential), BM cells containing $5.10^{4}$ human $\mathrm{CD} 45^{+} \mathrm{CD} 34^{+} \mathrm{CD} 19^{-}$cells were transplanted in secondary NSG mice. Human hematopoietic development in the secondary recipient mice was analyzed 13-16 weeks later. Human engraftment levels in mice receiving $20 \mathrm{mGy}$ and 2.5 Gy-irradiated BM cells were decreased compared to sham-irradiated BM cells (Figure 2A and Online Supplementary Figure S2D) showing that $20 \mathrm{mGy}$-irradiated BM cells are less efficient than non-irradiated $\mathrm{BM}$ cells to reconstitute human hematopoiesis in secondary recipient mice. However, in the 20 mGy condition, some human cells were still detected in the BM of secondary recipient mice. Among them, human B CD $19^{+}$lymphocytes and $\mathrm{CD} 14^{+} / \mathrm{CD} 15^{+}$myeloid cells were produced at the same proportion than in nonirradiated conditions, indicating that the few HSC that survived LDIR had maintained their differentiation capacities (Figure 2B). To exclude a non-cell autonomous effect of LDIR on HSPC mediated by irradiated hematopoietic or non-hematopoietic BM cells during the transplantation, we purified human $\mathrm{CD} 34^{+} \mathrm{CD} 38^{\text {low }}$ cells from the $\mathrm{BM}$ of control and $20 \mathrm{mGy}$-irradiated mice before transplantation in secondary NSG mice. As in the previous experiment, human cell engraftment in secondary recipients showed a reduced hematopoietic reconstitution capacity when 20 mGy-irradiated $\mathrm{CD} 34^{+} \mathrm{CD} 38^{\text {low }}$ cells were used (Figure 2C) and again no difference in the differentiation 
A

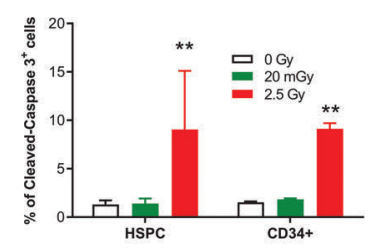

C

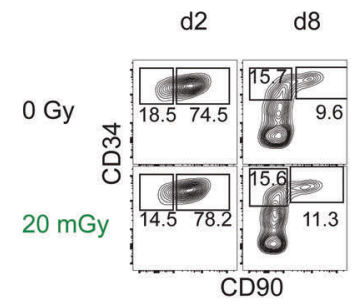

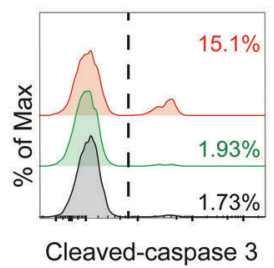

Cleaved-caspase 3

B
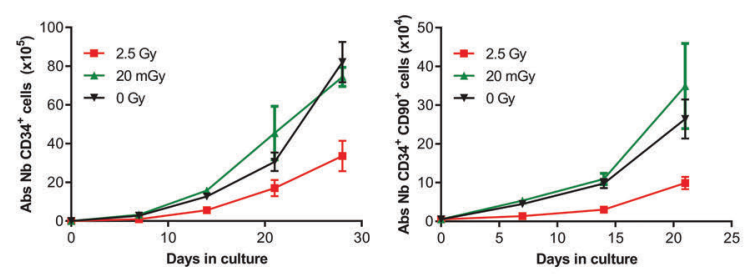

D

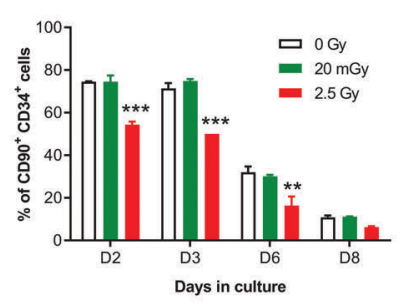

Gated in Lin ${ }^{\text {neg }}$ CD34+ CD90+ subset

E

Gated in live cells

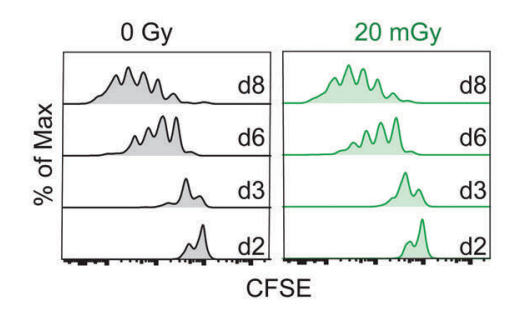
day 6
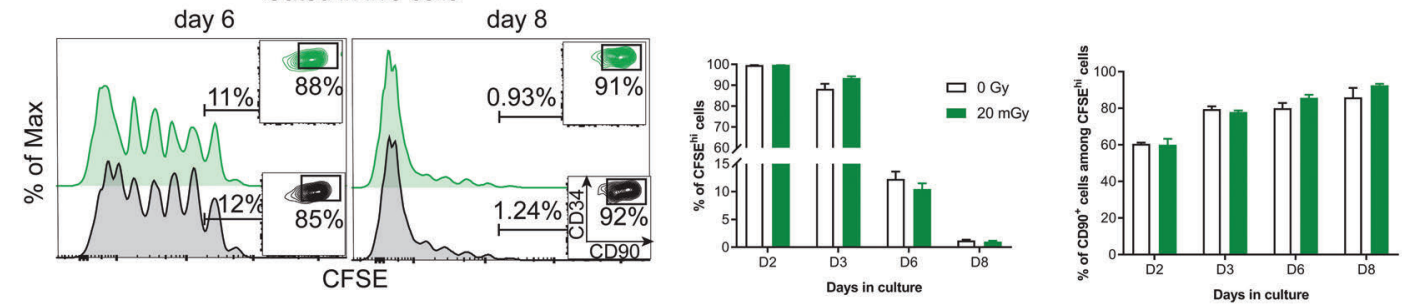

Figure 3. Low doses (LD) of ionizing radiations (IR) do not induce apoptosis and do not modify the cell cycle in human hematopoietic stem progenitor cells (HSPC). (A) CD34+ cells were irradiated and cultured for 6 hours $(\mathrm{h})$ at $37^{\circ} \mathrm{C}$, then stained for cell surface markers and fixed. Cleaved-caspase 3 protein expression was analyzed by FACS. Percentage of cleaved-caspase $3^{+}$cells on CD34 ${ }^{+}$CD $38^{\text {low }}$ CD45RA ${ }^{-}$CD90 $0^{+}$HSPC and on total CD34 ${ }^{+}$(left panel) and overlay histograms of cleavedcaspase 3 expression on HSPC (right panel) are represented in function of IR doses. One representative experiment out of two is shown. (B) Sorted CD34 ${ }^{+}$CD38 ${ }^{\text {low }}$ CD45RA-CD90 ${ }^{+}$HSPC were irradiated or not and co-cultured with MS5 stroma cell line for several days. At several time points, cells were numerated and stained for cell surface markers. The numbers of $\mathrm{CD} 34^{+}$cells (left) and $\mathrm{Lin}^{\text {neg }} \mathrm{CD} 34^{+} \mathrm{CD} 90^{+}$cells (right) were monitored over time. One representative experiment out of two is

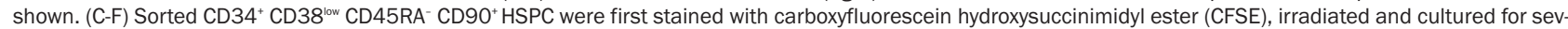

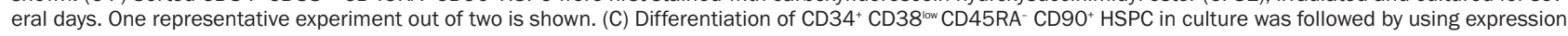
levels of CD90 and CD34 surface markers. Dot plots (left panel) represent CD90 and CD34 expression after 2 and 8 days of culture for control and 20 mGy-irradiated HSPC. Histogram bars (right panel) represent the percentage of Lin ${ }^{\text {neg }} \mathrm{CD} 34^{+} \mathrm{CD} 90^{+}$cells at different days of culture after IR. (D) Levels of carboxyfluorescein succinimidyl ester (CFSE) fluorescence in the $\mathrm{Lin}^{\text {neg }} \mathrm{CD} 34^{+} \mathrm{CD} 90^{+}$subset at different days of culture in control and 20 mGy conditions. No differences in cell division can be detected between both conditions. (E) Histogram representing CFSE staining in the HSPC-derived bulk cells at days 6 and 8 of culture in control and 20 mGy conditions (left panels). Histogram bars show CFSE labeling loss over culture time in the bulk population (right panel). (F) Percentage of Lin ${ }^{\text {neg }} \mathrm{CD} 4^{+} \mathrm{CD} 9 \mathrm{O}^{+}$cells in CFSE ${ }^{\text {hi }}$ cells in control and in 20 mGy conditions. Results are shown as mean \pm standard error of mean. $* \star P<0.01, * \star * P<0.001$ (Mann and Whitney statistics). Abs Nb: absolute numbers.

of the engrafted HSC was shown (Figure 2D) showing a cell-autonomous effect of LDIR in HSPC. Taken together these results indicate that $20 \mathrm{mGy}$ LDIR affects the hematopoietic reconstitution capacity of human HSPC.

\section{Low doses of ionizing radiations do not induce apoptosis nor alter cell cycle of hematopoietic stem/progenitor cells}

To characterize the mechanisms activated by $20 \mathrm{mGy}$ LDIR in human primary HSPC, we first investigated if LDIR trigger apoptosis. Analysis of caspase 3 cleavage showed that 2.5 Gy irradiation increases $\mathrm{CD} 34^{+} \mathrm{CD} 38^{\text {low }} \mathrm{CD} 45 \mathrm{RA} \mathrm{C}^{-} \mathrm{CD} 90^{+}$HSPC apoptosis (Figure $3 \mathrm{~A}$, red histograms), whereas 20 mGy LDIR had no significant effect on the percentage of cleaved caspase 3-expressing HSPC compared to sham-irradiated HSPC (Figure 3A, green histograms). As increased HSPC cell cycle can lead to self-renewal defects and HSC exhaustion, ${ }^{28}$ we also determined if 20 mGy LDIR could alter HSPC proliferation. 20 $\mathrm{mGy}$ and sham-irradiated $\mathrm{CD} 34^{+} \mathrm{CD} 38^{\text {low }} \mathrm{CD} 45 \mathrm{RA} \mathrm{CD}^{-} \mathrm{90} 0^{+}$
HSPC generated the same number of $\mathrm{CD}_{3} 4^{+}$and $\mathrm{CD} 34^{+} \mathrm{CD} 90^{+}$cells in vitro (Figure $3 \mathrm{~B}$, left and right panel, respectively) whereas 2.5 Gy-irradiated HSPC did not proliferate efficiently. Moreover, the proportion of $\mathrm{CD} 34^{+} \mathrm{CD} 90^{+}$cells evolved similarly during culture period after no irradiation or $20 \mathrm{mGy}$ LDIR, strengthening the lack of effect of a $20 \mathrm{mGy}$ irradiation on HSPC differentiation (Figure 3C). We studied the cell division rate of irradiated HSPC after staining with CFSE and during culture in serum free medium with cytokines. The number of cell divisions was the same for sham- or 20 mGy-irradiated HSPC (Figure 3D). After 6 and 8 days of culture, no difference in CFSE $^{\text {hi }}$ cell (the most immature cells) ${ }^{28}$ proportion was observed between 20 mGy and control HSPC (Figure 3E) and $90 \%$ of these CFSE ${ }^{\text {hi }}$ cells expressed the immature markers CD34 and CD9029 regardless of the culture time and irradiation conditions considered (Figure 3F). These results show that $20 \mathrm{mGy}$ LDRI does not impair either proliferation or differentiation of the most immature HSPC in cytokine-stimulating conditions. 
A

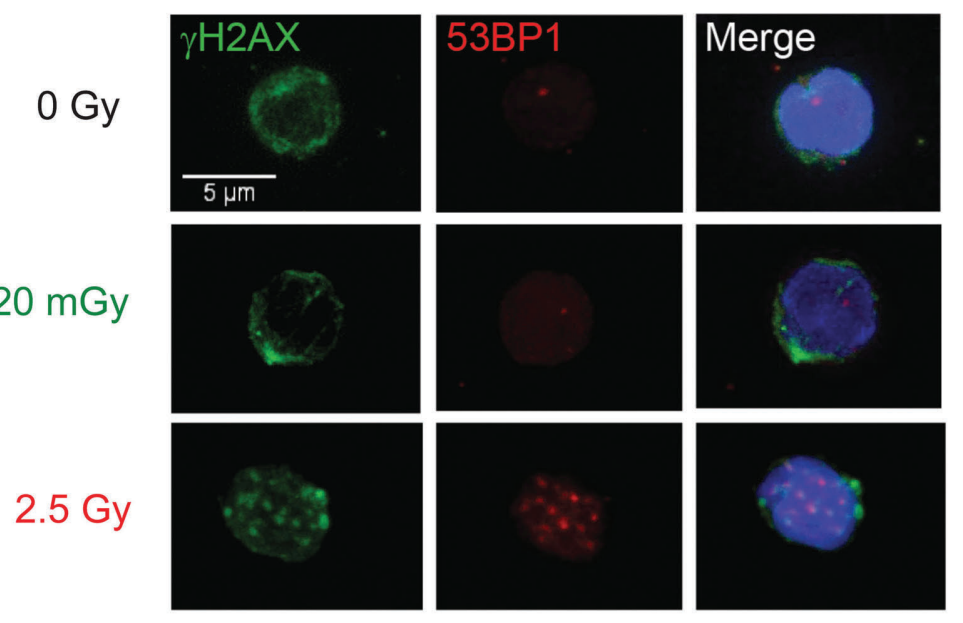

B
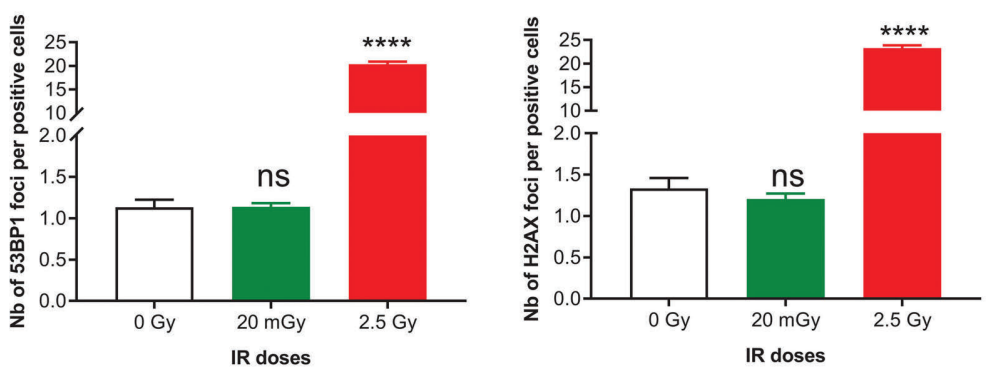

C

$10 \mathrm{~min}$ post-IR

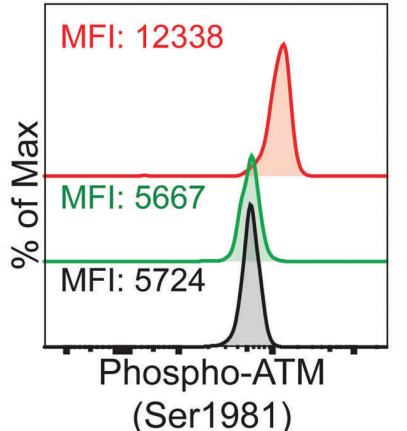

D

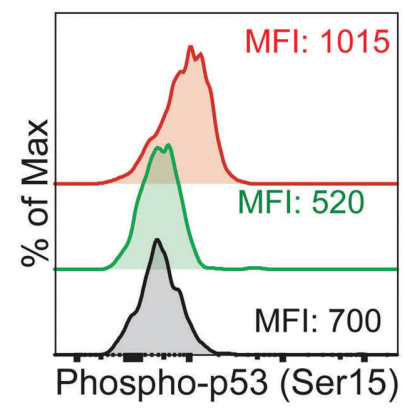

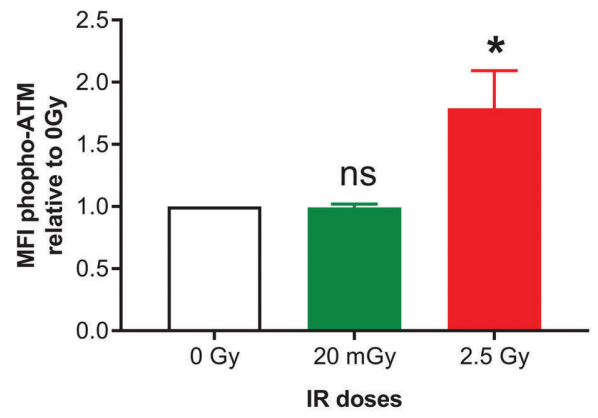

3h post-IR

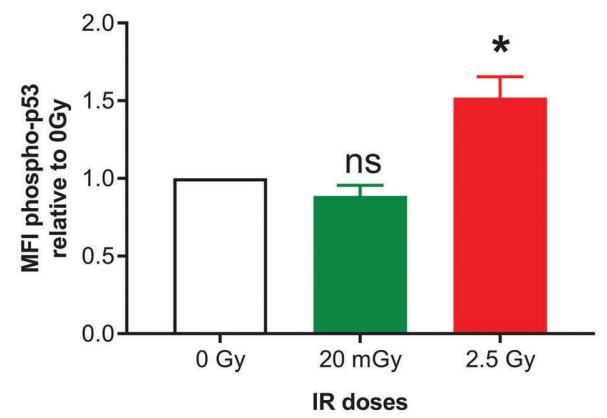

Figure 4. Low doses (LD) of ionizing radiations (IR) do not induce DNA double strand breaks nor activate ATMdependent/p53-dependent DNA repair pathway in human hematopoietic stem progenitor cells (HSPC). CD34+ ${ }^{+} \mathrm{CD} 38^{\text {low }}$ CD45RA- $\mathrm{CD}^{-} 0^{+} \mathrm{HSPC}$ were purified by cell sorting and exposed to different doses of IR as indicated. (A) $\gamma \mathrm{H} 2 \mathrm{AX}$ and 53BP1 foci were examined by confocal microscopy 30 minutes ( $\mathrm{min}$ ) post IR (at least 100 cells by condition were analyzed. (B) Number (Nb) of 53BP1 (left panel) and $\gamma \mathrm{H} 2 \mathrm{AX}$ (right panel) foci by positive HSPC. (C and D) $\mathrm{CD} 34^{+}$cells were irradiated, cultured $10 \mathrm{~min}(\mathrm{C})$ or 3 hours (h) (D) at $37^{\circ} \mathrm{C}$, stained for cell surface markers then fixed. (C) Analysis of ATM-phosphorylation on Ser1981 by FACS in CD34+ CD38 low CD45RA- CD90 ${ }^{+}$ HSPC (one representative experiment out of 4). (D) Analysis of p53-phosphorylation on Ser15 (left) and p53 protein expression (right) in $\mathrm{CD}_{3} 4^{+} \mathrm{CD} 38^{\text {low }}$ CD45RA- CD90+ HSPC by FACS $3 \mathrm{~h}$ post IR (one representative experiment out of $5)$. Results are shown as mean \pm standard error of mean. $* P<0.05$, $* * * * P<0.0001$ (Mann and Whitney statistics). 
A

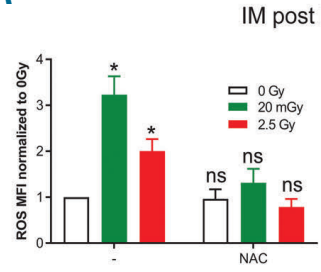

Treatments
IM post IR

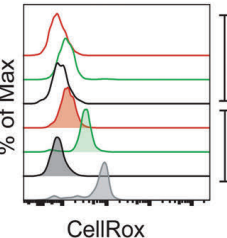

CellRox

C

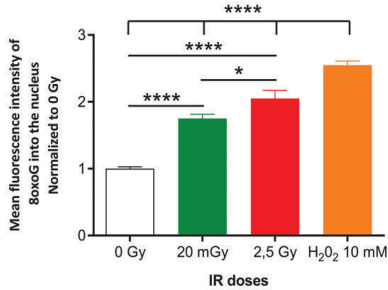

B

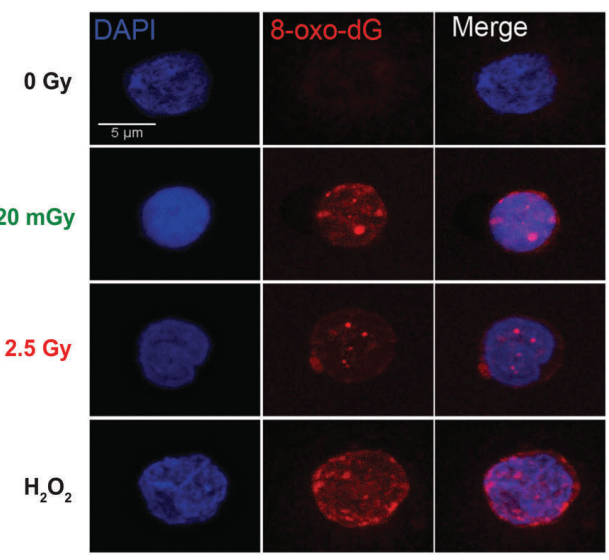

D

0 Gy

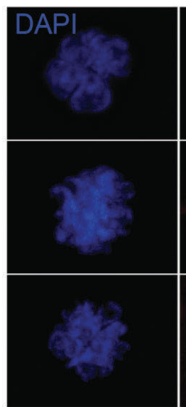

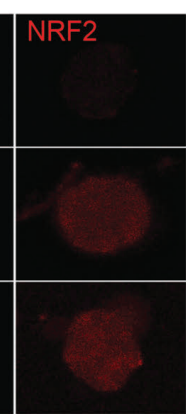

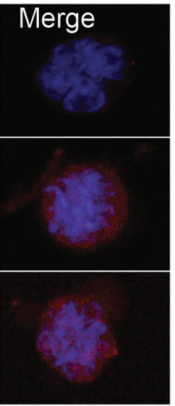

E
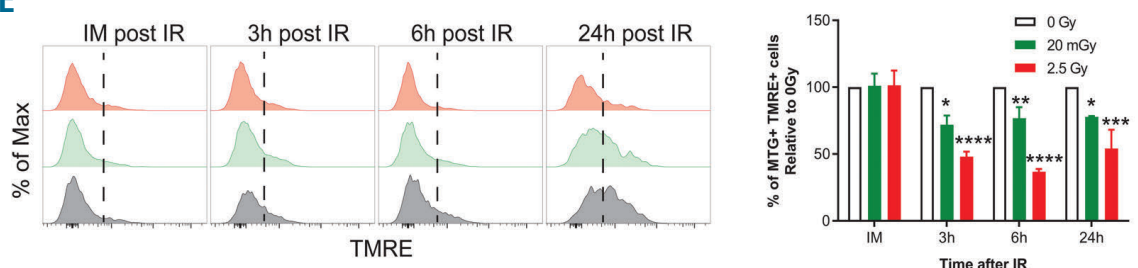

F

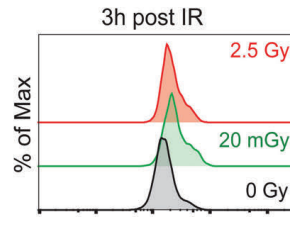

Phospho-p38MAPK
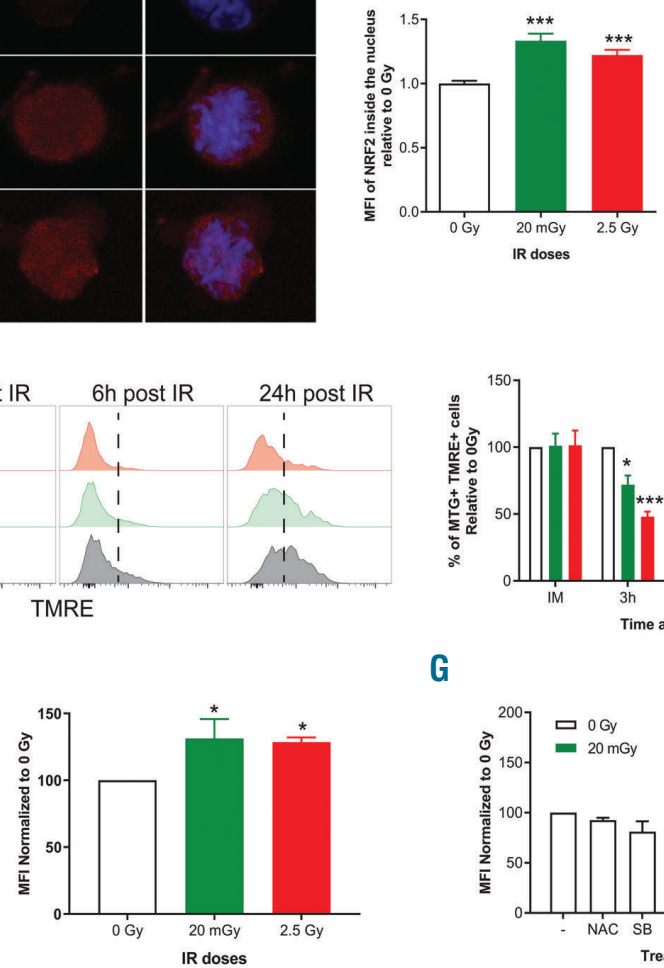

G

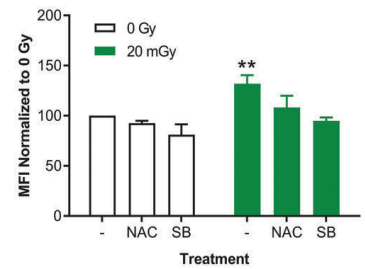

Figure 5. Low doses (LD) of ionizing radiations (IR) induce transitory reactive oxygen species (ROS) increase, 8-0xo-dG DNA lesions and p38MAPK activation with altered mitochondrial activity in hematopoietic stem progenitor cells (HSPC). (A) ROS levels were quantified in CD34 ${ }^{+}$CD38 ${ }^{\text {low }}$ CD45RA ${ }^{-}$CD90 ${ }^{+} \mathrm{HSPC}$ using CellRox Orange probe immediately after IR. (Left) Pool of CellRox Orange mean of fluorecence relative to 0 Gy condition, right overlay histograms showing CellRox Orange fluorescence. One representative experiment out of four is shown (see also Online Supplementary Figure S4). Results are shown as mean \pm standard error of mean. ( $\mathrm{B}$ and $\mathrm{C}$ ) $\mathrm{CD}_{34}{ }^{+} \mathrm{CD} 38^{\text {low }} \mathrm{CD} 45 \mathrm{RA}-\mathrm{CD} 90^{+} \mathrm{HSPC}$ were purified by cell sorting and exposed to different doses of IR or $\mathrm{H}_{2} \mathrm{O}_{2}$ as indicated. Shown are 8-oxo-dG lesions quantified by confocal microscopy 30 minutes post IR (at least 50 cells were screened by condition in 3 independent experiments. Blue: Dapi, Red: 8-oxo-dG). Histograms represent the intensity of fluorescence of 8-oxo-dG staining within HSPC nucleus. To avoid heterogeneity, mean fluorescence intensity (MFI) has been

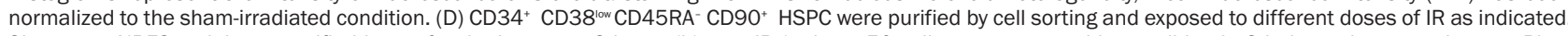
Shown are NRF2 staining quantified by confocal microscopy 2 hours (h) post IR (at least 50 cells were screened by condition in 2 independent experiments. Blue: Dapi, Red: NFR2). Histograms represent the intensity of fluorescence of NRF2 staining within HSPC nucleus. To avoid heterogeneity, MFI has been normalized to the sham-irradiated condition. (E) Mitochondrial activity was monitored over time by using TMRE (membrane potential, left panel) and MTG (mitochondrial mass) probes in HSPC. Shown is the frequency of TMRE ${ }^{+}$cells over time in culture for one representative experiment out of three independent experiments and the mitochondria activation (\% of $\mathrm{MTG}^{+} \mathrm{TMRE}^{+}$, right panel) over time in culture (pool of the 3 independent experiments). (F) $\mathrm{CD}^{2} 4^{+}$cells were irradiated and cultured $2 \mathrm{~h}$ at $37^{\circ} \mathrm{C}$ followed by cell surface marker staining and then fixed. Phosphorylation of p38MAPK on Thr180/Tyr182 was analyzed by flow cytometry. Overlay histograms of p38MAPK phosphorylation on CD34+ CD38 ${ }^{\text {low }}$ CD45RA- CD90 ${ }^{+} \mathrm{HSPC}$ (left panel) are represented for the three irradiation conditions. Overlay histograms are from one

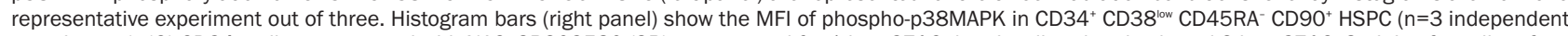
experiments). (G) CD34 cells were treated with NAC, SB203580 (SB) or untreated for $1 \mathrm{~h}$ at $37^{\circ} \mathrm{C}$ then irradiated and cultured $2 \mathrm{~h}$ at $37^{\circ} \mathrm{C}$. Staining for cell surface markers was performed and then cells were fixed. Phosphorylation of p38MAPK on Thr180/Tyr182 was analyzed by flow cytometry. Histogram bars show mean of fluorescence of phospho-p38MAPK in CD34+ ${ }^{+}$D38 ${ }^{\text {low }}$ CD45RA- CD90 HSPC ( $n=3$ independent experiments). Results are shown as mean \pm standard error of mean. $\star P<0.05, * * P<0.01, * * * P<0.001, * * * * P<0.0001$ (Mann-Whitney statistics). 
Low doses of ionizing radiations do not induce DNA double strand breaks nor activate ATM or p53 signaling pathway

Since irradiation usually induces DNA double strand breaks (DSB), we quantified the number of H2AX and 53BP1 foci $30 \mathrm{~min}$ post irradiation (Figure 4A). In contrast to a 2.5 Gy irradiation, a $20 \mathrm{mGy}$ irradiation did not increase the number of H2AX and 53BP1 foci compared to shamirradiated $\mathrm{CD}_{34}{ }^{+} \mathrm{CD} 38^{\text {low }} \mathrm{CD} 45 \mathrm{RA}{ }^{-} \mathrm{CD} 90^{+} \mathrm{HSPC}$ indicating that $20 \mathrm{mGy}$ LDIR does not induce DNA DSB (Figure 4B). We then studied the DNA damage response (DDR) path- way after exposure to LDIR by quantification of ATM and p53 phosphorylation $10 \mathrm{~min}$ and $3 \mathrm{~h}$ after irradiation. As expected, 2.5 Gy-irradiated HSPC exhibited an increased ATM and p53 phosphorylation compared to control HSPC (Figure $4 \mathrm{C}$ and D). In contrast, no increase in ATM or p53 phosphorylation was detected after exposure to 20 mGy (Figure 4C and D). Importantly, the expression of p53 protein was not modified by IR (Online Supplementary Figure S3). Altogether these results indicate that $20 \mathrm{mGy}$ LDIR does not induce DNA DSB nor activate p53 and ATM-dependent DNA damage repair pathway in human HSPC.
A

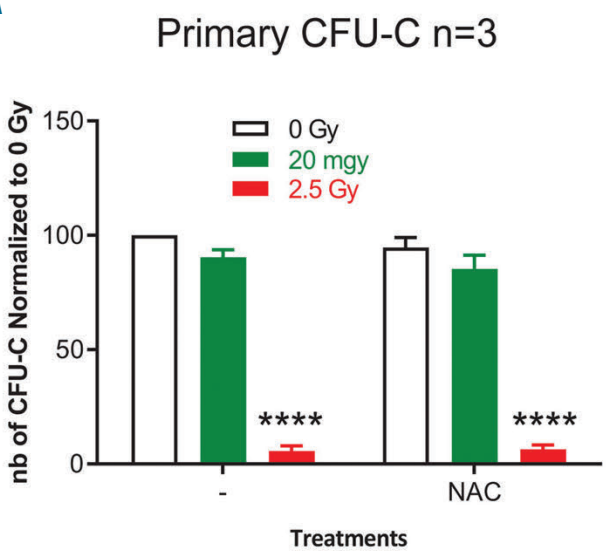

C

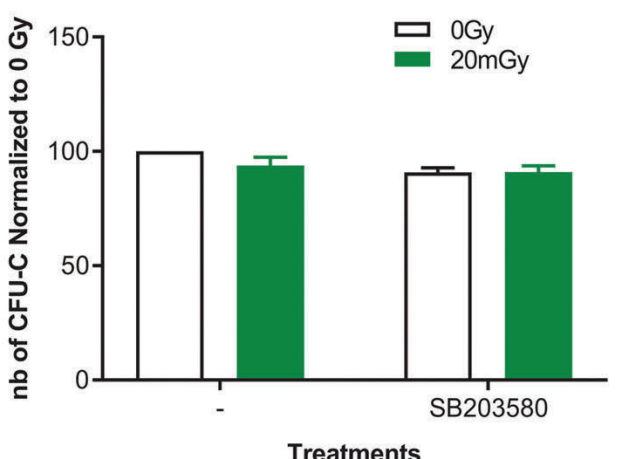

E
B

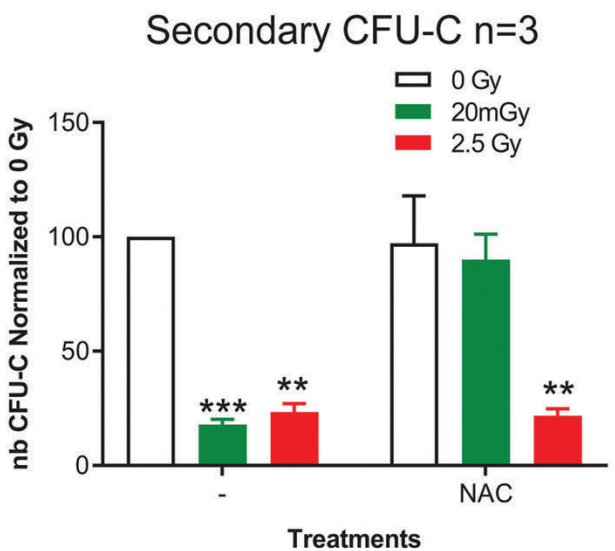

D

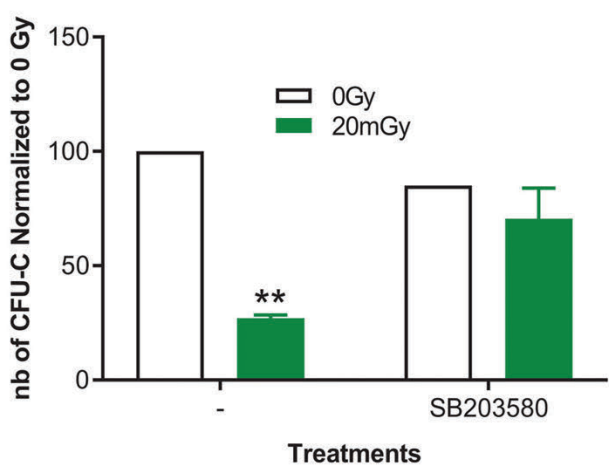

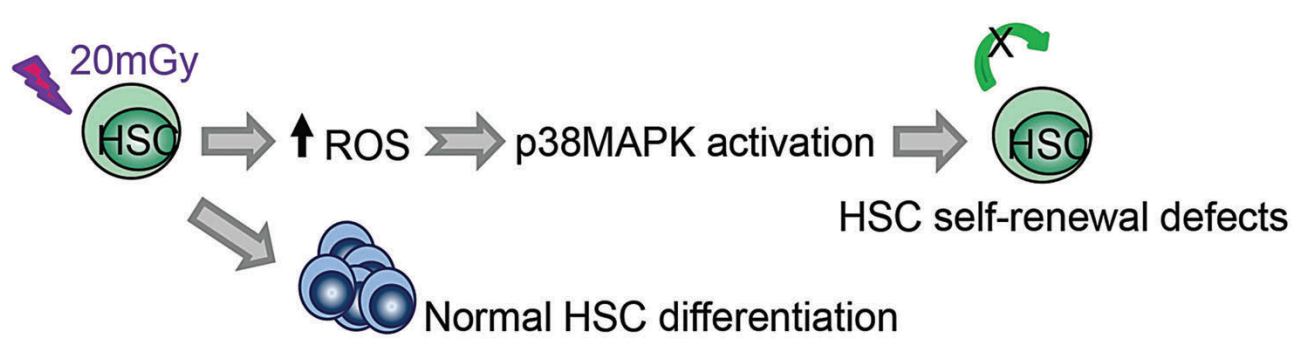

Figure 6. Low doses (LD) of ionizing radiations (IR) induce a transitory increase of ROS in CD $34^{+} \mathrm{CD}^{\circ} 8^{\text {low }} \mathrm{CD}{ }^{2} 5 \mathrm{RA}^{-} \mathrm{CD} 90^{+}$hematopoietic stem progenitor cells (HSPC) that alters their serial clonogenic potential. (A) Colony forming unit-cell (CFU-C) assay. Cumulative results from 3 independent experiments with CD34+ ${ }^{+}$CD38 ${ }^{\text {low }}$

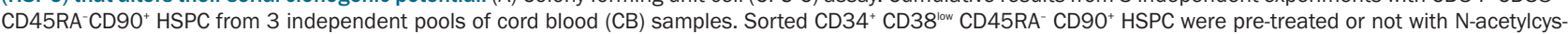
teine (NAC) prior to IR and plated (500 cells/plate) in CFU-C conditions for 12-14 days. Shown are the number (nb) of CFU-C (primary CFU-C). Results are normalized to the sham-irradiated conditions. (B) Primary CFU-C were pooled and replated in CFU-C conditions for 12-14 days. Shown are the nb of secondary CFU-C, normalized

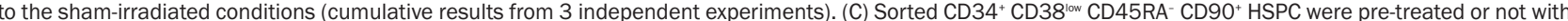
SB203580 prior to IR and plated (500 cells/plate) in CFU-C conditions for 12-14 days. Shown are the nb of CFU-C (primary CFU-C). Results are normalized to the sham-irradiated conditions. (D) Primary CFU-C were pooled and replated in CFU-C conditions for 12-14 days. Shown are the nb of secondary CFU-C, normalized to the sham-irradiated conditions (cumulative results from 2 experiments with $\mathrm{CD}^{3} 4^{+} \mathrm{CD} 38^{\text {low }} \mathrm{CD} 45 \mathrm{RA} \mathrm{C}^{-} \mathrm{CD} 90^{+} \mathrm{HSPC}$ from two independent pools of $\mathrm{CB}$ samples. (E) Model explaining how LDIR can impair HSC self-renewal through ROS-p38MAPK dependent pathway. Results are shown as mean+standard error of mean. $* * P<0.01$ $* * * P<0.001, * * * * P<0.0001$ (Mann- Whitney statistics). 
Low doses of ionizing radiations increase reactive oxygen species levels, 8-oxo-dG lesions, induce NRF2 translocation into the nucleus, activate p38MAPK pathway and delay mitochondrial activation

Since irradiation is known to promote ROS production, ${ }^{10,18,30}$ we next quantified ROS levels after LDIR exposure. ROS levels in $\mathrm{CD} 34^{+} \mathrm{CD} 38^{\text {low }} \mathrm{CD} 45 \mathrm{RA}^{-} \mathrm{CD} 90^{+} \mathrm{HSPC}$ after exposure to LDIR were measured immediately or 3 $\mathrm{h}$ after irradiation of $\mathrm{CD} 34^{+}$cells. Menadione and NAC treatments were used to respectively induce and inhibit ROS production. Increased ROS levels in HSPC were observed immediately after exposure to $20 \mathrm{mGy}$ LDIR and to a lesser extent after exposure to $2.5 \mathrm{~Gy}$, as compared to no irradiation (Figure 5A and Online Supplementary Figure S4A and B). These ROS increased levels were transient as no further difference in ROS levels could be detected $3 \mathrm{~h}$ after irradiation (Online Supplementary Figure S4C). NAC pretreatment of HSPC significantly decreased this early burst of ROS after 20 $\mathrm{mGy}$ and 2.5 Gy exposure. As increased ROS levels can lead to 8-oxo-dG lesions, as well as NRF2 translocation into the nucleus, we looked for 8-oxo-dG lesions in DNA of irradiated versus sham-irradiated HSPC $^{30,31}$ and NRF2 location into HSPC. ${ }^{22,24}$ As expected sham-irradiated and $\mathrm{H}_{2} \mathrm{O}_{2}$-treated (control) cells exhibited respectively no and highly detectable anti-8-oxo-dG nuclear labeling. After exposure to $20 \mathrm{mGy}$, 8-oxo-dG staining was detected in the HSPC nucleus showing that $20 \mathrm{mGy}$ LDIR can induce 8-oxo-dG lesions in DNA (Figure 5B and C). Similarly, the NRF2 protein was found in the nucleus of 20 mGy- and 2.5 Gy-irradiated HSPC compared to shamirradiated cells (Figure 5D). As an increase in ROS is also associated with a delay in mitochondrial activation, ${ }^{32}$ we used mitotracker green (MTG) and TMRE probes to study respectively mitochondrial mass and membrane potential. Of note, $\mathrm{CB} \mathrm{CD} 34^{+}$cells and $\mathrm{CB}$ HSPC are mainly quiescent, therefore there is very little mitochondrial activation (TMRE ${ }^{\text {neg }}$ ) (Figure 5E, first left panel, and data not shown). HSPC exposure to LDIR did not alter the mitochondrial mass (MTG) of CD34+ cells in short-term culture (Online Supplementary Figure S5A). However, a delay in mitochondrial activation occurred $\left(\mathrm{MTG}^{+}\right.$ $\mathrm{TMRE}^{+} \mathrm{HSPC}$ ) as soon as $3 \mathrm{~h}$ post IR (Figure $5 \mathrm{E}$ and Online Supplementary Figure S5B), suggesting that LDIR affect mitochondrial activity. In line with mitochondria activation, autophagy activation was monitored after IR (Online Supplementary Figure S6). The CytoID probe was used to follow autophagy in HSPC. ${ }^{33,34}$ As expected, after treatment with chloroquine and rapamycine, autophagy was detected in $\mathrm{CD} 34^{+}$cells (Online Supplementary Figure S6A). Besides, LDIR did not induce autophagy in HSPC after a different culture time (Online Supplementary Figure $S 6 B$ and C). Finally, we investigated whether the observed increase of ROS can lead to p38MAPK activation as previously documented. ${ }^{19}$ Thr180/Tyr18 phosphorylation was used as a marker of p38MAPK activation. As a positive control of p38MAPK activation, increased p38MAPK phosphorylation (P-p38MAPK) can be detected in PMA-treated HSPC (Online Supplementary Figure S5C). In irradiated HSPC, we observed an increase of P-p38MAPK after exposure to $20 \mathrm{mGy}$ and 2.5 Gy IR compared to sham-irradiated controls, suggesting that LDIR can activate p38MAPK pathway in HSPC similarly to high irradiation doses (2.5 Gy) $)^{35}$ (Figure 5F). To further confirm that p38MAPK acti- vation was due to the early transient increase in ROS levels, HSPC were treated with NAC or SB203580, a p38MAPK inhibitor, prior to $20 \mathrm{mGy}$ irradiation. As expected, SB203580 prevented increased p38MAPK phosphorylation in $20 \mathrm{mGy}$-irradiated HSPC (Figure 5G). NAC treatment resulted in the same decrease in p38MAPK phosphorylation in $20 \mathrm{mGy}$-irradiated HSPC (Figure 5G). Altogether, these results show that LDIR increase ROS levels leading to DNA 8-oxo-dG lesions, NRF2 translocation into the nucleus and p38MAPK activation in 20 mGy-irradiated HSPC.

\section{0 mGy-dependent reactive oxygen species increase and p38MAPK activation lead to defects in the serial clonogenic potential of hematopoietic stem/progeni- tor cells}

As increased ROS levels can lead to HSC loss of potentials ${ }_{1}^{18}$ we then asked if ROS-dependent pathways could explain the HSPC functional defects after LDIR exposure. To this end, serial CFU-C assays were performed using sorted $\mathrm{CD} 34^{+} \mathrm{CD} 38^{\text {low }} \mathrm{CD} 45 \mathrm{RA} \mathrm{C}^{-} \mathrm{CD} 90^{+} \mathrm{HSPC}$ pre-treated or not with NAC before exposure to LDIR and cultures. 20 mGy-irradiated HSPC generated the same number of primary CFU-C compared to sham-irradiated HSPC with or without NAC treatment (Figure 6A and Online Supplementary Figure S7A). However, $20 \mathrm{mGy}$-irradiated HSPC treated with NAC before IR, but not 2.5 Gy-irradiated cells, were capable of generating equivalent numbers of secondary CFU-C compared to sham-irradiated HSPC, showing that NAC treatment prior to exposure to 20 mGy protected HSPC from the loss of in vitro serial clonogenic potential (Figure 6B and Online Supplementary Figure $S 7 B)$. This result was obtained when the serial plating assays were performed with the whole cell population harvested from primary CFU cultures (Figure 6B), and also after picking up and replating individual primary CFU-GM colonies (Online Supplementary Figure S7C). Rescue of secondary replating properties of HSPC after 20 mGy LDIR was also obtained using HSPC pretreatment with Catalase, another antioxidant enzyme (Online Supplementary Figure S7D). These results show that preventing ROS production with antioxidants before LDIR exposure rescues the in vitro serial clonogenic potentials of HSPC.

Finally, we wondered whether ROS-mediated p38MAPK activation was involved in LDIR-induced HSC self-renewal defects. HSPC were pre-treated with SB203580, a specific inhibitor of p38MAPK, prior to 20 mGy irradiation and serial CFU-C assays. No difference in the number of primary CFU-C was detected with SB203580 pretreated HSPC regardless of the irradiation dose used (Figure 6C and Online Supplementary Figure S7E). However, whereas SB203580-untreated $20 \mathrm{mGy}$ irradiated HSPC generated very few secondary CFU-C, SB203580 treatment of HSPC protected their capacity to generate secondary CFU-C as efficiently as sham-irradiated HSPC (Figure 6D and Online Supplementary Figure $S 7 F)$, suggesting that $\mathrm{p} 38 \mathrm{MAPK}$ pathway activation participates in LDIR-mediated HSPC defects. Based on all these results, we propose a model in which $20 \mathrm{mGy}$ LDIR rapidly increases ROS amounts in HSPC that induce p38MAPK activation altogether leading to a defect in the long-term maintenance of the clonogenic potential of $\mathrm{CD} 34^{+} \mathrm{CD} 38^{\text {low }} \mathrm{CD} 45 \mathrm{RA}^{-} \mathrm{CD} 90^{+} \mathrm{HSPC}$ (Figure 6E). 


\section{Discussion}

Here we show that exposure to a single $20 \mathrm{mGy}$ LDIR alters the functional properties of human HSPC. No defect in HSPC differentiation potential tested in primary cultures was detected after exposure to LDIR. However, HSPC irradiated at $20 \mathrm{mGy}$ in vivo in the NSG mouse BM harbored a defect in human hematopoietic reconstitution potential. This defect was cell-intrinsic since $20 \mathrm{mGy}$-irradiated $\mathrm{CD} 34^{+} \mathrm{CD} 38^{\text {low }}$ cells isolated after in vivo irradiation failed to serially reconstitute NSG mice as efficiently as non-irradiated cells; the same was observed with in vivo 20 mGy-irradiated bulk BM cells. This in vivo phenotype was also observed in vitro when using LDIR-exposed $\mathrm{CD} 34^{+} \mathrm{CD} 38^{- \text {-low }} \mathrm{CD} 45 \mathrm{RA}^{-} \mathrm{CD} 90^{+} \mathrm{HSPC}$ in serial CFU-C and LTC-IC assays, supporting the fact that these effects are cell-autonomous and not limited to transplantation conditions. Likewise, in vitro, HSPC exposure to $20 \mathrm{mGy}$ induced a loss of secondary CFU-C potential as well as a decrease in secondary LTC-IC frequency. Altogether, based on the use of in vivo assays and in vitro surrogate assays to evaluate the self-renewal potential, ${ }^{25-27}$ these functional results strongly argue for an effect of $20 \mathrm{mGy}$ LDIR on the long-term HSC functional properties, most likely through a loss of self-renewal potential. Of note, 20 mGy LDIR has been shown to decrease self-renewal capacity in murine HSC as well. ${ }^{22}$

High-dose ionizing radiations (HDIR) (2.5 Gy) are known to induce DNA DSB in human HSPC, rejoining is delayed, and H2AX foci persist leading to a loss of HSC functions partly related to apoptosis and activation of p53 pathway. ${ }^{23}$ Despite the publication of several studies over the past few years, ${ }^{36-38}$ little is known about which pathway is used to repair DNA DSB in human HSPC. ${ }^{16}$ In the present work, we tested if a single $20 \mathrm{mGy}$ LDIR can alter cell cycle and induce apoptosis, and cause DNA DSB in HSPC. Surprisingly, and in contrast to HDIR, 20 mGy irradiation did not induce obvious cell cycle defects nor promote apoptosis in HSPC, since no increased cleaved caspase 3 protein was detected after exposure to $20 \mathrm{mGy}$ LDIR. Moreover, no significant increase in $\mathrm{H} 2 \mathrm{AX}$ and 53BP1 foci numbers was revealed, suggesting that $20 \mathrm{mGy}$ LDIR does not produce DNA DSB. Finally, neither p53 nor ATM pathway was activated after 20 mGy exposure. However, and similarly to HDIR, $20 \mathrm{mGy}$ irradiation led to 8-oxo-dG lesions in HSPC DNA. No such lesion was observed in sham-irradiated cells. Altogether, $20 \mathrm{mGy}$ LDIR does not induce classic DNA damage and repair pathways usually activated by $\gamma$-irradiation but rather triggers 8-oxo-dG-dependent DNA damage that can be linked to uncontrolled increase in ROS levels. Moreover, NRF2 protein was found in the nucleus of $20 \mathrm{mGy}$-irradiated HSPC. Indeed, increased ROS levels were detected immediately after HSPC exposure to $20 \mathrm{mGy}$ and, in line with this, we could observe that 20 mGy-irradiated HSPC had a delay in mitochondrial activation compared to control cells. Our results and those from Romeo's lab ${ }^{22}$ suggest that the transient increase in ROS levels is likely to be responsible for HSPC defects after LDIR exposure. We tested this hypothesis using antioxidant treatment of HSPC prior to exposure to LDIR. Importantly, pre-treatment of HSPC with NAC or Catalase prior to LDIR exposure did rescue the loss of in vitro serial clonogenic potential of HSPC. In mouse, irradiation can induce p38MAPK activation through increased levels of ROS. ${ }^{19,35}$ Prevention of p38MAPK activation leads to decreased IR toxicity in HSC ${ }^{35}$ It is also known that dormant HSC have little or no p38MAPK activation, and that p38MAPK activation in HSC is associated with differentiation and loss of HSC self-renewal. ${ }^{17,39}$ In humans, the function of the p38MAPK pathway is still not fully understand but preventing p38MPAK activation allows HSC maintenance/expansion in vitro. ${ }^{40,41}$ Interestingly, in our model, we observed a ROSdependent p38MAPK activation in human HSPC after exposure to both $2.5 \mathrm{~Gy}$ and $20 \mathrm{mGy}$ IR. The involvement of the p38MAPK pathway in the LDIR-mediated HSC self-renewal defects was then confirmed in serial replating CFU-C assays. Indeed, pre-treatment of HSPC with a specific inhibitor of p38MAPK prior to LDIR rescued their serial replating capacities. This is in agreement with the fact that HSC treatments either with NAC or p38MAPK inhibitor increase LTC-IC frequency and promote higher hematopoietic reconstitution upon serial transplantation. ${ }^{18,19}$ It is important to highlight that two other studies on the effect of LDIR have also shown that LDIR did not induce classic DNA damage and repair pathways, but rather an oxidative stress (increase in ROS level and NRF2 nuclear localization) ${ }^{22,42}$ Therefore, oxidative stress induction seems to be a feature of exposure to LDIR, leading either to a differentiation defect in the case of cycling stem cells ${ }^{42}$ or a self-renewal defect in the case of quiescent stem cells, as we observed for human HSPC; this is also the case for mouse HSC.22

Increased ROS levels as well as p38MAPK activation in HSC are associated with aging and stress during serial transplantation..$^{17,18,43}$ The aging phenomenon is clearly a strong driver of differentiation and expansion of myeloid-biased HSPC. ${ }^{44}$ Here we were not able to detect any bias toward myelopoiesis when analyzing the progeny of the surviving LDIR-treated human HSC after serial transplantation, maybe due to the NSG mouse model, as the NSG BM microenvironment is more supportive of B-cell rather than myeloid-cell differentiation. ${ }^{45}$ Moreover, all experiments were performed with HSPC from CB, i.e. young HSPC. Thus, although it is tempting to speculate that exposure to LDIR may induce early/accelerated aging of the human HSC, we have no formal proof of that. Since radiation sensitivity and transplantation efficiency are highly dependent on the ontogenic origin of HSPC, ${ }^{46-48}$ aged HSPC may be more sensitive to LDIR. Another feature of HSC aging is higher risk of leukemic transformation, especially in the presence of an oncogenic-initiating event such as a mutation of the epigenetic modifiers DNMT3a or TET2, as observed in blood from elderly people. ${ }^{49} \mathrm{~A}$ very interesting and important question for the future would be to determine if aged HSC exposed to LDIR are more prone to (pre)leukemic transformation, especially when HSC contain primary oncogenic mutations.

To sum up, in contrast to HDIR, $20 \mathrm{mGy}$ does not induce DNA DSB, nor apoptosis and a defect in the cell cycle. However, both $20 \mathrm{mGy}$ and 2.5 Gy IR induce 8-oxo-dG lesions in DNA, increase ROS levels, and activate the p38MAPK pathway leading to HSC self-renewal defects. Nevertheless, only 20 mGy-LDIR effects were counteracted by use of antioxidants prior to irradiation exposure, indicating there are major differences between these two IR doses. These results show for the first time that a dose as low as $20 \mathrm{mGy}$ can have a huge impact on human HSC through both similar and also different molecular mechanisms to those of high IR doses. 


\section{Acknowledgments}

We acknowledge the midwives from Clinique des Noriets in Vitry-sur-Seine and the Cell therapy department of Hôpital Saint Louis in Paris, France, especially Prof. J. Larghero, for providing cord blood samples free of charge and the families who agreed to donate the samples for research purposes. This work was made possible thanks to multiple platforms (Flow cytometry, Microscopy, Irradiation and animal facilities) of IRCM, Fontenay-aux-Roses, France. We are thus grateful to J Tilliet and $N$ Dechamps for their great technical help during this project. A special thanks to J Bernardino and JB Lahave for their devoted work at the irradiation platform from IRCM but also to C. Villagrasa, Y. Ristic and M. Razanajotovo-Derichebourg for their precious help at the irradiation platform, laboratory of dosimetry of ionizing radiation, IRSN, Fontenay-aux-Roses, France. Finally, we acknowledge Paul-Henri Roméo, Franck Yates, Christophe Carles, Benjamin Uzan and Rima Haddad for helpful discussions and manuscript reviewing.

\section{Funding}

This study was supported by grants from INSERM, CEA (Segment Radiobiologie), Ligue Nationale contre le Cancer (équipe labellisée from 2014 to 2017), Région Ile de France/Cancéropole, Electricité de France and the European network RISK-IR. I-SS was supported by the European network RISK-IR and EH is a PhD fellow from the Ligue Nationale Contre le Cancer.

\section{References}

1. Mendelson A, Frenette PS. Hematopoietic stem cell niche maintenance during homeostasis and regeneration. Nat Med. 2014; 20(8):833-846.

2. Doulatov S, Notta F, Laurenti E, Dick JE. Hematopoiesis: a human perspective. Cell Stem Cell. 2012;10(2):120-136.

3. Majeti R, Park CY, Weissman IL. Identification of a hierarchy of multipotent hematopoietic progenitors in human cord blood. Cell Stem Cell. 2007;1(6):635-645.

4. Arcangeli ML, Frontera V, Bardin F, et al. JAM-B regulates maintenance of hematopoietic stem cells in the bone marrow. Blood. 2011;118(17):4609-4619

5. Yu VW, Scadden DT. Hematopoietic Stem Cell and Its Bone Marrow Niche. Curr Top Dev Biol. 2016;118:21-44

6. Benyoucef A, Calvo J, Renou L, et al. The SCL/TAL1 Transcription Factor Represses the Stress Protein DDiT4/REDD1 in Human Hematopoietic Stem/Progenitor Cells. Stem Cells. 2015;33(7):2268-2279.

7. Brunet de la Grange P, Armstrong F, Duval $\mathrm{V}$, et al. Low SCL/TAL1 expression reveals its major role in adult hematopoietic myeloid progenitors and stem cells. Blood. 2006; z108(9):2998-3004.

8. Correia NC, Arcangeli ML, Pflumio F, Barata JT. Stem Cell Leukemia: how a TALented actor can go awry on the hematopoietic stage. Leukemia. 2016; 30(10):1968-1978.

9. Orkin SH. Diversification of haematopoietic stem cells to specific lineages. Nat Rev Genet. 2000;1(1):57-64.

10. Ito K, Hirao A, Arai F, et al. Regulation of oxidative stress by ATM is required for selfrenewal of haematopoietic stem cells. Nature. 2004;431(7011):997-1002.

11. Nijnik A, Woodbine L, Marchetti C, et al. DNA repair is limiting for haematopoietic stem cells during ageing. Nature. 2007; 447(7145):686-690.

12. Rossi DJ, Bryder D, Seita J, Nussenzweig A, Hoeijmakers J, Weissman IL. Deficiencies in DNA damage repair limit the function of haematopoietic stem cells with age. Nature. 2007;447(7145):725-729.

13. Cheng T, Rodrigues N, Dombkowski D, Stier S, Scadden DT. Stem cell repopulation efficiency but not pool size is governed by p27(kip1). Nat Med. 2000;6(11):1235-1240.

14. Matsumoto A, Takeishi S, Kanie T, et al. p57 is required for quiescence and mainte- nance of adult hematopoietic stem cells Cell Stem Cell. 2011;9(3):262-271.

15. Zou P, Yoshihara H, Hosokawa K, et al. p57(Kip2) and p27(Kip1) cooperate to maintain hematopoietic stem cell quiescence through interactions with Hsc70. Cell Stem Cell. 2011;9(3):247-261.

16. Biechonski S, Milyavsky M. Differences between human and rodent DNA-damage response in hematopoietic stem cells: at the crossroads of self-renewal, aging and leukemogenesis. Transl Cancer Res. 2013; 2(5):372-383

17. Jang YY, Sharkis SI. A low level of reactive oxygen species selects for primitive hematopoietic stem cells that may reside in the low-oxygenic niche. Blood. 2007;110(8):3056-3063.

18. Yahata T, Takanashi T, Muguruma Y, et al. Accumulation of oxidative DNA damage restricts the self-renewal capacity of human hematopoietic stem cells. Blood. 2011; 118(11):2941-2950

19. Ito K, Hirao A, Arai F, et al. Reactive oxygen species act through p38 MAPK to limit the lifespan of hematopoietic stem cells. Nat Med. 2006;12(4):446-451.

20. Pearce MS. Patterns in paediatric CT use: an international and epidemiological perspective. J Med Imaging Radiat Oncol. 2011;55(2):107-109.

21. Pearce MS, Salotti JA, Little MP, et al. Radiation exposure from CT scans in childhood and subsequent risk of leukaemia and brain tumours: a retrospective cohort study. Lancet. 2012;380(9840):499-505

22. Rodrigues-Moreira S, Moreno SG, Ghinatti $\mathrm{G}$, et al. Low-dose irradiation promotes persistent oxidative stress and decreases self-renewal in hematopoietic stem cells. Cell Rep. 2017;20(13):3199-3211.

23. Milyavsky M, Gan OI, Trottier M, et al. A distinctive DNA damage response in human hematopoietic stem cells reveals an apoptosis-independent role for p53 in selfrenewal. Cell Stem Cell. 2010;7(2):186-197.

24. Picou F, Debeissat C, Bourgeais J, et al. n-3 Polyunsaturated fatty acids induce acute myeloid leukemia cell death associated with mitochondrial glycolytic switch and Nrf2 pathway activation. Pharmacol Res. 2018;136:45-55.

25. Hao QL, Thiemann FT, Petersen D, Smogorzewska EM, Crooks GM. Extended long-term culture reveals a highly quiescent and primitive human hematopoietic progenitor population. Blood. 1996;88(9):33063313.
26. Petzer AL, Hogge DE, Landsdorp PM, Reid DS, Eaves CJ. Self-renewal of primitive human hematopoietic cells (long-term-culture-initiating cells) in vitro and their expansion in defined medium. Proc Natl Acad Sci U S A. 1996;93(4):1470-1474

27. Rizo A, Dontje B, Vellenga E, de Haan G, Schuringa JJ. Long-term maintenance of human hematopoietic stem/progenitor cells by expression of BMI1. Blood 2008;111(5):2621-2630.

28. Nakamura-Ishizu A, Takizawa H, Suda T. The analysis, roles and regulation of quiescence in hematopoietic stem cells. Development. 2014;141(24):4656-4666.

29. Notta F, Doulatov S, Laurenti E, Poeppl A, Jurisica I, Dick JE. Isolation of single human hematopoietic stem cells capable of longterm multilineage engraftment. Science. 2011;333(6039):218-221.

30. Walter D, Lier A, Geiselhart A, et al. Exit from dormancy provokes DNA-damageinduced attrition in haematopoietic stem cells. Nature. 2015;520(7548):549-552.

31. Haghdoost S, Czene S, Naslund I, Skog S, Harms-Ringdahl M. Extracellular 8-oxo-dG as a sensitive parameter for oxidative stress in vivo and in vitro. Free Radic Res. 2005;39(2):153-162.

32. Cabon L, Bertaux A, Brunelle-Navas MN, et al. AIF loss deregulates hematopoiesis and reveals different adaptive metabolic responses in bone marrow cells and thymocytes. Cell Death Differ. 2018;25(5):9831001.

33. Chabi S, Uzan B, Naguibneva I, et al. Hypoxia regulates lymphoid development of human hematopoietic progenitors. Cell Rep. 2019;29(8):2307-2320.e6.

34. Gomez-Puerto MC, Folkerts H, Wierenga AT, et al. Autophagy Proteins ATG5 and ATG7 Are Essential for the Maintenance of Human CD34(+) Hematopoietic StemProgenitor Cells. Stem Cells. 2016; 34(6):1651-1663.

35. Wang Y, Liu L, Zhou D. Inhibition of $\mathrm{p} 38$ MAPK attenuates ionizing radiationinduced hematopoietic cell senescence and residual bone marrow injury. Radiat Res. 2011;176(6):743-752

36. de Laval B, Pawlikowska P, Petit-Cocault L, et al. Thrombopoietin-increased DNA-PKdependent DNA repair limits hematopoietic stem and progenitor cell mutagenesis in response to DNA damage. Cell Stem Cell. 2013;12(1):37-48

37. Kraft D, Rall M, Volcic M, et al. NF-kappaBdependent DNA damage-signaling differ- 
Exposure to $20 \mathrm{mGy}$ radiation decreases HSC functions

entially regulates DNA double-strand break repair mechanisms in immature and mature human hematopoietic cells. Leukemia. 2015;29(7):1543-1554.

38. Sha L, Fen W, Lee KJ, Chen BP, Chou D. A sensitive and quantitative polymerase chain reaction-based cell free in vito nonhomologous end joining assay for hematopoietic stem cells. PLo One. 2012;7(3):e33499.

39. Tesio M, Tang $\mathrm{Y}$, Nuder $\mathrm{K}$, et al. Hematopoietic stem cell quiescence and function are controlled by the CYLDTRAF2-p38MAPK pathway. J Exp Med. 2015;212(4):525-538.

40. Baudet A, Karlsson C, Safaee Talkhoncheh M, Galeev R, Magnusson M, Larson J. RNA screen identifies MAPK14 as a druggable suppressor of human hematopoietic stem cell expansion. Blood. 2012;
119(26):6255-6258.

41. Zou J, Zou P, Wang J, et al. Inhibition of p38 MAPK activity promotes ex vive expansion of human cord blood hematopoietic stem cells. Ann Hematol. 2012;91(6):813-823.

42. Fernandez-Antoran D, Piedrafita G, Murai $\mathrm{K}$, et al. Outcompeting p53-Mutant Cells in the Normal Esophagus by Redox Manipulation. Cell Stem Cell. 2019;25(3):329-341.e6.

43. Rube CE, Fricke A, Widmann TA, et al. Accumulation of DNA damage in hematopoietic stem and progenitor cells during human aging. PLo One. 2011;6(3):e17487.

44. Akunuru S, Geiger H. Aging, Clonality, and Rejuvenation of Hematopoietic Stem Cells. Trends Mol Med. 2016;22(8):701-712.

45. Ito R, Takahashi T, Katano I, Ito M. Current advances in humanized mouse models.
Cell Mol Immunol. 2012;9(3):208-214.

46. Hernandez L, Terradas M, Camps J, Martin M, Tusell L, Genesca A. Aging and radioion: bad companions. Aging Cell. 2015;14(2):153-161.

47. Holyoake TL, Nicolini FE, Eaves CJ. Functional differences between transplantable human hematopoietic stem cells from fetal liver, cord blood, and adult marrow. Exp Hematol. 1999;27(9):1418-1427.

48. Kollman C, Howe CW, Anasetti C, et al. Donor characteristics as risk factors in recipients after transplantation of bone marrow from unrelated donors: the effect of donor age. Blood. 2001;98(7):20432051.

49. Xiv M, Lu C, Wang J, et al. Age-related mutations associated with clonal hematopoietic expansion and malignancries. Nat Med. 2014;20(12):1472-1478.

haematological | 2020; 105(8)

2055 